\title{
NARASI THEOLOGIS DALAM KIDUNG PANCA YAJŇA
}

\author{
Ni Nyoman Suastini \\ STKIP Agama Hindu Singaraja, \\ ninyomansuastini123@gmail.com
}

\begin{abstract}
ABSTRAK
Upacara yang berkualitas adalah upacara yang memenuhi tujuh syarat, yaitu: Sradha, Lascarya, Sastra, Daksina, Mantara dan Gita, Anasewa dan Naasmita. Dari ketujuh syarat tersebut salah satunya adalah Mantra dan Gita. Mantra adalah doa-doa yang dilafalkan oleh pemimpin (Manggala) upacara, sedangkan Gita (kidung) dilantunkan oleh seorang atau sekelompok orang yang terhimpun dalam organisasi (sekaa) Pesantian. Kidung (gita) yang dinyanyikan disesuaikan dengan jenis upacara, serta rangkaian (alur) upacara. Kidung Panca Yajnya (Gita) tersebut menguraiakan tentang berbagai manifestasi Tuhan (Hyang Widhi) yang diharapkan berkenan hadir dalam upacara yang diselenggarakan, serta berkenan menerima persembahan umatnya, serta berkenan pula menurunkan berkahnya. Sesuai dengan kitab suci Weda manifestasi Tuhan (Para Dewa) banyak jumlahnya sesuai dengan kemahakuasaan Tuhan. Secara vertikal para Dewa yang menguasai dan menjiwai alam semesta beserta isinya ini disebut Sang Hyang Tiga Sakti, dan secara horizontal yang menguasai Sembilan penjuru mata angin disebut Dewata Nawa Sanga yaitu penguasa sembilan penjuru mata angin yang diumpamakan sebagai "Bunga Teraratai" dengan sembilan kelopaknya dan menjadi areal stana Dewa masing masing sesuai dengan sembilan arah penjuru mata angin. Disamping itu juga secara khusus Dewa Siwa dinyatakan sebagai penguasa Tri Bhuwana.
\end{abstract}

Kata kunci: Narasi Theologis, Kidung Panca Yajna.

\section{ABSTRACT}

A ceremony that entrusted is ceremony that fulfill seven requirements, such as: Sradha, Lascarya, Sastra, Daksina, Mantara and Gita, Anasewa dan Naasmita. From that seven requirements one of the are Mantra and Gita. Mantra are prayes that is pronounciated by the ceremony leadern (Manggala), meanwhile Gita (kidung) is chanted by the people or group of people that gathered in the organization (sekaa) called Pesantian. Kidung (gita) that is sung appropriate with the type of ceremony, and the sequence (plot) of the ceremony. Kidung Panca Yajnya (Gita) elaborate about various manifest of God (Hyang Widhi) that is expected to come in the ceremony that will be done, and agree to take the people's offerings, and also agree to decrease the blessing. Based on the Weda scripture, God manifest are so many in numbers based on the God omnipotence. Vertically, Gods that dominate and animate the universe and its content called Sang Hyang Tiga Sakti, and horizontally called Dewata Nawa Sanga that is the lord of the nine cardinal points which is likened to the Lotus Flower with nine petals and be an area from the God itself based on nine cardinal points. Beside that specially Siwa God is stated as Tri Bhuwana ruler.

Keywords: Theological Narrative, Song of Panca Yajna. 


\section{PENDAHULUAN}

Umat Hindu di Indonesia khususnya di Bali, didalam menjalankan Sradhabhaktinya kepada Tuhan (Hyang Widhi) sebagian besar dengan melaksanakan Bakti Marga yaitu mewujudkan rasa bhakti kehadapan Tuhan dengan menggelar upacara yang lumrah dilaksanakan, yaitu upacara Panca Yadnya (lima jenis korban suci). Upacara yang dilaksanakan sesuai dengan kemampuan masing masing Yajamana. Dan upacara yajnya yang dianggap berkualitas adalah upacara yang memenuhi tujuh syarat yaitu: Sradha, Lascarya, Sastra, Daksina, Mantara dan Gita, Anasewa dan Naasmita. Dari ketujuh syarat tersebut salah satu diantaranya adalah mantra dan gita.

Mantra dan Gita sangat penting dalam upacara. Setiap upacara yang berkualitas haruslah ada Mantra dan Gita (lagu lagu suci untuk pemujaan) yang diucapkan umat, Pinandhita dan Pandhita sesuai dengan aturannya. (Wiana, 2006:27). Khusus di Bali, Gita tersebut lumrah disebut Kidung Panca Yajnya.

Hyang Widhi menurunkan ajaranNya berupa Wahyu (sabda suci) yang diterima oleh para maha Rsi dan didokumentasi dalam kitab suci Weda berupa petunjuk pelaksanaan upacara dan petunjuk hidup dalam bertingkah laku di masyarakat, berupa pedoman Tata Susila (sesana), serta pedoman atau cara dalam mewujudkan rasa dan sikap bhakti (acara) kepadaNya. Disamping itu kitab suci juga memberikan penjelasan tentang hakekat Hyang Widhi serta cara untuk memahamiNya dan bagaimana caranya untuk bisa menyatu kembali kepada Beliau.

Berkaitan dengan cara melaksanakan kebaktian atau pemujaan Bhagawata Purāna menyebutkan bahwa ada sembilan cara yang bisa dilakukan dalam memuja Tuhan seperti berikut

"Śravanam̉ Kirtanam̉ Vișṇuh,

Smaranam Padasevanam,

Arhanam Vandanam Dāsyam,

Sakyam Atmanivedanam (Bhagawata Purana, VII. 5.23 dalam Surada, 2006:v).

"Śravanaṁ adalah suatu kegiatan bhakti untuk memuja Ida Hyang Widhi Wasa dengan jalan mendengarkan cerita cerita suci keagamaan dan mendenarkan pembacaan mantra mantra ayatayat suci Veda. Kirtanam Vișnuh adalah kegiatan bhakti untuk memuja Ida Hyang Widhi dengan jalan menyanyikan atau melantunkan kidung-kidung suci keagamaan, atau mempelajari keagungan Tuhan melalui membaca atau mendengarkan pembacaan kitab suci. Smaranam adalah kegiatan bhakti kepada Ida Sang Hyang Widhi dengan jalan selalu mengingat nama nama Tuhan dengan segala manifestasiNya, atau menyanyikan nama-nama Tuhan yang Maha Esa.Padasevanam adalah kegiatan bhakti kepada Tuhan dengan mengabdi pada kakiNya. Atau mengabdi kehadapannya dengan melayani ciptaanNya pula. Archanam adalah kegiatan bhakti kepada Tuhan melalui media archa atau pratima sebagai nyasa karena Tuhan bersifat gaib, dengan mempersembahkan berbagai persembahan. Vandanam adalah kegiatan bhakti kepada Tuhan dengan jalan membaca ayat-ayat suci Tuhan serta cerita suci keagamaan (sujud bakti atau kebaktian). Dāsyam adalah kegiatan bhakti kepada Tuhan dengan jalan mengabdi atau menjadi pelayan Tuhan. Termasuk mengabdi kepada yang memerlukan pelayanan dalam menjalankan bhaktinya. Sakyam adalah kegiatan bhakti kepada Tuhan dengan jalan membina hubungan dengan Tuhan layaknya sebagai seorang sahabat, atau memandang Tuhan sebagai sahabat sejati yang siap memberikan pertolongan. Atmanivedanam adalah kegiatan bhakti kepada Tuhan dengan jalan penyerahan diri secara bulat kepada Tuhan.

Menyanyikan kidung-kidung pujaan (kirtanam) yang dilantunkan saat diadakan persembahyangan (Panca Yajnya), memiliki manfaat yang sangat mendalam karena disamping dapat melahirkan suasana yang religius (suci) juga mampu memberikan "narasi" atau penjelasan kepada umat tentang eksistensi Hyang Widhi serta berbagai prabhawanya, yang dijadikan obyek 
ritual dan pemujaan, sehingga keyakinan umat dapat semakin mantap dan meningkat. Disamping itu umat juga akan dapat memahami prosesi serta makna upakara dan upacara yang dilakukan dan upakara yang dipersembahkan.

Pada awalnya Weda diwahyukan keduania adalah berbentuk Sruti, yang diterima secara lisan dan disampaikan secara lisan pula. Mengingat pada saat Weda diturunkan manusia belum mengenal tulisan, jadi bahasa lisan lebih dahulu dipergunakan barulah kemudian ketika diciptakan tulisan mantra-mantra Weda dituliskan kembali. Penulisan kembali weda tersebut secara tradisional berdasarkan kitab-kitab purāna, Mahā Rsi Vyasa atau Kṛṣnadvipāyaṇa yang menyusun atau menuliskan kembali ajaran Veda dalam 4 himpunan (samhita) yang dibantu oleh 4 orang siswanya yaitu: Pulaha atau Paila diyakini menyusun Rg veda, Vaiśampayana menyusun Yajurveda, Jaimini menyusun Sāmaveda dan Sumantu menyusun Atharvaveda (Titib, 1996:25).

Weda tidak hanya dijadikan pedoman dalam menjalani atau meningkatkan kehidupan kerohanian (spiritual), tetapi Weda juga dijadikan pedoman hidup bermasyarakat berbangsa dan bernegara karena Weda itu sendiri sebagai sumber hukum kehidupan. Namun terkait dengan kehidupan masa sekarang dimana negara hanya menerapkan hukum positif dalil-dalil agama hanya dijadikan sebagai pelengkap pembuktian semata. Oleh karena itu aktifitas dan penerapan ajaran-ajaran agama (Hindu) khususnya hanya tampak dalam pelaksanaan etika (moral), filsafat (tatwa) dan upacara keagamaan saja.

Dalam pelaksanaan upacara agama tampak memang suatu sajian yang harmonis terbalut dalam suatu kesatuan harmonis (etis, estetis, filosofis dan didaktis). Etis karena setiap upacara agama (Panca Yajnya) memiliki pedoman tersendiri baik secara tradisi maupun yang tertulis berupa lontar-lontar dan buku-buku untuk dapat menghasilkan sebuah upacara yang bernilai satwika. Setiap rangkaian (dudonan) harus dilaksanakan secara sistematis terurut dari awal hingga akhir upacara dengan struktur "utpati, stithi dan pralina", uttpati yaitu suatu prosesi menghadirkan/menstanakan Tuhan dan Prabhawanya (para dewa/dewi) berikutnya adalah stithi yaitu menstanakan dan mempersembahkan suatu persembahan serta melakukan berbagai pujian/pemuliaan, dan prosesi yang terakhir adalah pralina yaitu mengembalikan Tuhan dan manifestasinya ke alamnya (sunya loka). Sri Rsi Ananda Kusuma, (1986: ). Disamping itu perilaku Sang Yajamana (penyelenggara upacara) juga harus sesuai dengan etika yang meliputi perilaku pikiran (manacika parisudha), perkataan (wacika parisudha) dan perbuatan (kayika parisuda) harus semuanya terjaga kesuciannya (tri kaya parisudha).

Setiap upacara keagamaan senantiasa didukung oleh kesenian (estetika) baik itu seni reringgitan (upakara) yang digunanakan dalam upacara sebagai uparengga, seni tari (wali dan Balihbalihan) seni tabuhm(karawitan), seni suara (dharma gita) dan juga beberapa seni lukis (patra) dan seni bangunan. Semuanya itu termasuk kedalam unsur estetis (estetika). Upacara agama juga harus menggunakan landasan filosofis tertentu yaitu Weda (secara otoritas) atau sumber yang tidak bertengtangan dengan suci kitab suci weda. Dan memiliki makna filosofi atau memvisualkan kembali nilai nilai filosofis melalui upacara agama yang diselenggarakan. Hal ini sesuai dengan kerangka dasar agama Hindu yaitu tatwa, susila dan upacara (upakara).

Secara keseluruhan baik perilaku (etika) dalam berupacara dan penampilan beberapa kesenian panca gita yaitu kesenian (seni tari, karawitan) dan kidung kidung suci yang dilantunkan dapat memberikan pendidikan yang bersifat rohani dan etika kepada umat. Terkait dengan nilai didaktis dalam kidung banyak diungkapkan bahkan sampai kepada hal hal yang bersifat theologis (filosofis), karena secara eksplisit kidung mewacanakan hakekat Hyang Widhi (Tuhan beserta manifestasinya). Menurut Teori ni ada beberapa hal yang menyebabkan manusia berprilaku serbag religi. Menurut Koentjaraningrat dalam bukunya Antropologi Soaial menyebutkan bahwa system ritual atau tiap tiap upacara keagamaan terdiri dari lima unsure, yaitu: (1) system keyakinan, (2) tempat upacara (3) saat upacara (4) benda benda dan alat alat upacara, dan 
(5) orang orang yang melakukan upacara (1990:241). Senada dengan pernyataan tersebut dikatakan bahwa Paling tidak ada lima unsure religi yaitu: (1) emosi keagamaan/eligious emotion/getaran jiwa yang menyebabkan manusia menjalankan kelakuan keagaman, (2) system kepercayaan/bilive system atau baying baying manusia tentang bentuk dunia, alam, alam gaib, hidup, mati dan sebagainya; (3) sitem upacara keagamaan yang bertujuan mencari hubungan dengan duniagaib berdasarkan atas system kepercayaan; (4) peralatan dan perlengkapan upacara; (5) kelompok keagamaan/religious community atau kesatuan kesatuan social yang mengonsepsikan dan mengaktifkan religi beserta sitem upacara keagamaannya (Sugeng Puji Leksono, 2006:91-92).

\section{METODE PENELITIAN}

Jenis Penelitian ini adalah penelitian kualitatif yaitu sebuah penelitian berdasarkan peristiwa yang terjadi di lapangan yaitu suatu aktifitas ritual atau upacara (Panca Yajnya) yang senantiasa diiringi dengan kidung yang disebut Kidung Panca Yajnya. Penelitian ini juga menggunakan sumber sumber tertulis yang merupakan naskah Kidung Panca Yajnya yang dijadikan literasi dalam melakukan kidung tersebut. Penemuan merupakan kegiatan yang sangat penting dalam suatu penelitian. Dalam kegiatan penelitian dikenal adanya dua jenis data yaitu (1) data primer yaitu data yang didapat secara langsung dari obyek penelitian dan (2) data sekunder yaitu data yang didapat dari obyek secara tidak langsung. Data primer umumnya berlaku pada bagi penelitian lapangan (field research) sedangkan data sekunder pada umumnya berlaku bagi peneliti. (Titib, 2003:3).

Metode penemuan data dalam penelitian ini adalah metode kepustakaan, yang dimaksud dengan metode kepustakaan (library metod) adalah mengadakan kajian dan penelusuran terhadap sumber sumber kepustakaan yang dijadikan subyek penelitian (Sutrisno, 1982: 21, dalam Titib 2003:4). Karena penelitian ini termasuk penelitian kepustakaan (library research). Data diambil dari naskah naskah kidung Panca Yajnya, yang dijadikan (dilantunkan ) pada setiap penyelenggaraan Upaca Panca Yajnya, yaitu upacara: Bhuta Yajnya, Manusya Yajnya, Pitra Yajnya, Rsi Yajnya dan Upacara Dewa Yajnya. Setelah dilakukan pengumpulan data, maka langkah selanjutnya adalah melakukan analisa data. Seperti telah disebutkan di depan bahwa penelitian ini adalah merupakan penelitian kepustakaan, maka data yang diperoleh dari pustakapustaka atau naskah-naskah yang dijadikan obyek penelitian maka data yang didapatkan adalah katakata atau syair -syair kidung Panca Yajnya yang dikaji dengan menggunakan sumber sumber teologi.

\section{HASIL DAN PEMBAHASAN}

Theologi atau Brahma Widya adalah ilmu tentang Tuhan (Titib, 2003:14). Selanjutnya disebutkan Tuhan bersifat Imanen (Saguna, Sakala) dan Transendent (Nirguna, Niskala, Sunia). Namun demikian masyarakat sering memberikan penafsiran tentang manifestasi Tuhan sesuai dengan kemampuan nalarnya, dan umumnya bersifat lokal. Namun jika dikaji secara lebih dalam tidak bertentangan dengan yang tersurat dalam naskah naskah sastra agama. Tuhan itu esa adanya, para bijaksanalah memberikan nama atau abhisekanama yang berbeda beda, seperti: Agni, Indra, Vayu dan lain lain, seperti dinyatakan dalam kutipan berikut:

Indram mitra varunam agnim ahur

Atho divyas sa supasno garutman,

Ekam sadvipra bahudhavadanty

Agnim yamam matarisvama ahuh

(Veda I.164.46 dalam Titib,14:2003) 
Artinya:

Mereka menyebutNya dengan Indra. Mitra, Varuna dan

Agni. la yang bersayap keemansan Garuda, la adalah esa,

Para Maharsi (viprah) memberinya banyak nama, mereka

menyebut Indra, Yama, Matarisvan

Selanjutnya disebutkan bahwa di Bali banyak ditemukan sebuah lontar yang berjudul Widhi Papincatan yang berisi keputusan-keputusan hukum/pengadilan semacam Yurisprudensi. Demikian juga Lontar Widhisastra yang berarti pengetahuan tentang Widhi (teologi), dan juga dalam lontar susastra Jawa Kuna yang lainnya. Widhi adalah Tuhan sebagai Widhi disebut bersthana di Luhuring Akasa, yakni diatas angkasa, nun jauh disana. Dalam pengertian ini, tentu Tuhan Yang Maha Esa digambarkan tidak berwujud (inpersonel God). Kapan Sang Hyang Widhi dimohon turun dan hadir untuk menerima persembahan, maka saat itu beliau telah berwujud dalam alam pikiran. Wujud utamaNya disebut Tri Murti (Brahma, Visnu dan Siva) dalam Matram (Titib, 15: 2003).

Dalam Bhuvana Sanksepa dalam (Titib, 30:2003) disebutkan tentang Devata Nawa (Nawa) Sanga:
1. Utara
: Visnu
2. Timur
: Iswara
3. Barat
: Mahadewa
4. Selatan
: Brahma
5. Timur Laut: Sambu
6. Tenggara
: Mahesvara
7. Barat Daya
: Rudra
8. Barat Laut
: Sangkara

Dalam Mantram Pujastawa Kusuma Dewa disebutkan Sebagai berikut:

Om Iswara Purwantu Dewa,

Gneyantu Maha Dewa,

Nerityamtu Rudra Dewa,

Pascimantu Maha Dewa,

Bhayanbyantu Sankaranca,

Uttarantu Wisnu Dewa,

Ersanyantu Sambhu Dewa,

Madya Adah Siwa Dewa,

Madya Sada Siwa Dewam,

Sarwa Dewa Muktyante,

Om Om Shri Dewa Dewi Maha amerttaya namo namah swaha

(SRI RESHI ANANDHA KUSUMA, 43-44, 1986)

Artinya:

Om Dewa Iswara dari arah timur, dari arah Selatan Dewa Brahma, dari barat Laut Dewa Rudra, dari arah barat Dewa Maha dewa, dari arah barat laut Dewa Sangkara, dari arah uttara Dewa Wisnu, dari timur laut Dewa Sambhu, dari tengah Dewa Siwa, dari tengah atas Dewa Sada Siwa, Semua Dewa Maha Suksma, Om Om shri Dewa Dewi, Maha Amretta Pasupataye namah swaha.

Berdasarkan pengamatan penulis atas data yang ditemukan dalam beberapa naskah kidung Panca Yajnya, memuat Narasi Theologis Hindu (uraian tentang para Dewa sebagai manifestasi/prabhawa Tuhan) yang diharapkan kehadirannya untuk mennikmati persembahan suci 
sebagai berikut: 1). Tuhan dalam prabhawa sebagai Tiga Sakti, 2). Tuhan dalam Prabhawa sebagai Dewata Nawa Sanga.

\section{Narasi Theologis Tuhan dalam Manifestasi sebagai Sang Hyang Tiga Sakti}

Ida Hyang Widhi (Tuhan) memang tidak berwujud (Acintyarāpa) yang artinya tidak berwujud dalam alam pikiran manusia (Monier dalam Titib, 2003:10). Eksistensi Tuhan yang dalam keadaan tanpa bentuk dan tidak terpikirkan dalam kitab Tatwa Ĵnana disebutkan sebagai berikut:

"Paramasiwatattwa ngaranya kasthityan bhatara ring niskala, tan polah, tan limbak, tan laku, tan hili, tan pasangkan, tan pangaran, tan pawitan, tan pawkasan kewala sthiti, umideng, humeneng, humeneng langgeng juga sira, ibek tang rat kabeh denira, kakasut kahmu kawyapaka juga sira, kabeh tang sapta bwana de nira, sapta patala sandul wuntu sesek pnuh lyab kang jagat denira, tan kawenang lingonan, tan kawenang tinambenan, niskarya nisprayojana juga sira, tan para wyapara ring hala hayu, nir huningan ta sira ika kabeh, mwang tan hana gatintanagata wartamana nira, tan kahletan sira dening kala, rahina sada juga sira, tanpa kahilangan lana juga sira, nahan laksana bhatara Parama Siwatattwa, yeka kasthitiyan bhatara ring niskala ika, sira ta bhatara Parama Swa Tattwa ngaran nira"

Artinya:

Paramasiwatattwa adalah Bhatara dalam keadaan tanpa bentuk, tidak bergerak, tidak guncang, tidak pergi, tidak mengalir, tidak ada asal, tidak ada tempat yang dituju, tidak berawal dan tidak berakhir, hanya tetap tak brgerak tenang tanpa gerak. Diam dan kekal. Seluruh alam semesta ini dipenuhinya, diliputi, disangga, disusupi diseluruh sapta buwana (tujuh lapis dunia) ini oleh-Nya, Sapta patala disusupi sepenuh penuhnya, tiada ruang yang terisi, tiada ruang yang tidak terisi, penuh terisi alam semesta ini oleh-Nya Tidak dapat dikurangi, tidak dapat ditambahkan, Tanpa karya juga tanpa tujuan. Tidak dapat diganggu oleh perbuatan baik ataupun buruk. Tak dapat dikenal keseluruhannya. Dan tidak mengenal masa lalu, masa yang akan datang dan masa kini. Tidak dirintangi oleh waktu, selalu siang tidak sesuatu hilang pada- Nya. la kekal abadi. Demikianlah sifat sifat Bhatara Paramesiwatattwa.

Itulah keberadaaan Bhatara di alam niskala ialah Bhatara Paramasiwatattwa, dalam kidung Dewa Yajnya disebutkan seperti kutipan berikut:

1. Pangradane ka luhur, Maka pangundang Dewane, Asep menyan majagau, Ambunnyane mrik sumirit, Candana pada masanding, Pamendake ring Bhatarane, ne munggah ka luhur, Ngaran Tiga Sakti.

2. Sada Siwa Majagau, Parama Siwa Cendanane, Menyannyane batara Guru, Anduse nepud ka langit, punika anggen pamargi, pacang turun ring Kahyangan, Mangda gelis Artinya: rawuh, Manusa manyiwi. (...........................)

1. Permohonan ke atas, sebagai pengundang para dewa, dengan asap menyan gaharu, aromanya harum semerbak, disertai cendana, sebagai sarana penyambutan kehadapan para Dewa dan Bhatara, yang tertuju ke atas adalah Sang Hyang Tiga Sakti.

2. Sada Siwa dengan gaharu, Parama Siwa dengan cendana, menyan mengunndang Bhatara Guru, asapnya menembus langit, itu sebagai mediaNya, Beliau turun ke Kahyangan, supaya segera tiba, pada pemujaNya.

Dalam kidung Panca Yajnya Tuhan yang Maha Esa beserta manifestasiNya (PrabhawaNya), semuanya diuraikan dengan jelas sesuai dengn „atributnya" masing masing. Dan kesmuanya itu mendapat pemujaan yang sama oleh umat Hindu, dengan berbagai bentuk ritual 


\section{Narasi Theologis dalam Manifestasi Tuhan sebagai Dewata Nawa Sanga Dalam Kidung Panca Yajnya}

Khusus bagi manggala upacara (Pinandhita atau Pandhita) yang memimpin upacara dimaksud, terlebih dahulu beliau menyampaikan permohonan ke atas (ke luhur) sebagai permohonan kepada para Dewa, dengan sarana upakara berupa asep menyan gaharu beserta cendana yang beraroma harum semerbak untuk menyongsong para dewa yang disebut Tiga Sakti yaitu Dewa Sada Siwa, Dewa Parama Siwa dan Dewa dan Bhatara Guru, jadi asap dari menyan cendana dan gaharu dianggap sebagai „jalan" (media) para Dewa "turun menuju kahyangan".

Selanjutnya secara filosofis Tuhan bersifat Wibhu Sakti (memenuhi seluruh alam semesta) termasuk dengan semua manifestasinya seperti yang disebutkan dalam kidung di atas. Disamping itu beliau juga Maha Mendengar (Dura Srawana) Melihat semuanya (Dura Darsana) dan mengetahui segalanya (Jnana Sakti) sehingga apapun permohonan umatNya selalu dilihat dan didengar dan diyakini merestui permohonan umatnya sehingga beliau datang dari berbagai penjuru sesuai dengan arah dan kiblat posisinya masing masing seperti dari arah timur Hyang Iswara bersenjatakan bajra dan berbusana putih, dari arah muncul Dewa Brahma berwana merah bersenjata Gada, dari arah barat Dewa Maha Dewa besenjatakan Naga Pasa berwarna kuning keemasan, dari arah utara Dewa Wisnu bersenjatakan Cakra berwarna hitam dan dari arah tengah Dewa Siwa amanca warna bersenjatakan Padma. Dari Tenggara beliau muncul Dewa Sang Hyang Sambu bersenjatakan Tri Sula busananya serba warna abu abu, dari barat daya hadirlah Dewa Sang Hyang Rudra Murti bersenjatakan Angkus dan busananya serba merah kwanta. Dari Barat Daya beliau muncul Sanghyang Sangkara dengan senjata umbul umbul berwarna hijau.

Dalam kidung Panca Yadnya disebutkan sebagai berikut:

a. Sakeng purwa Ida rawuh, Bajrotama senjatane, Petak busanane nerus, Sang Hyang Iswara kapuji, Sakeng Daksina Umijil, Sanjatane Gada kawot, Busana bang murub, Hyang Brahma kapuji.

b. Ring Pascima Ida turun, Nagapasa sanjatane, Kuning busanane mulus, Sang Hyang Maha Dewa wiakti, Ring Uttara Ida mijil, Sanjatane Cakra mulia, Ida Sang Hyang Wisnu, Ireng busananeki.

c. Ring Madia Batara tedun, Padma Mreta senjatane, Busanane warna brumbun, Betara Siwa Siniwi, Ring Padmasana alinggih prabhawane tejoma, Ujwala seumunu kadatwaning langit.

d. Sakeng kajakangin rawuh, Tri Sula sanjatane, Kang kawuwus Sang Hyang Sambu, Busanane klau sari.

e. Rawuh sakeng kelod kauh, Angkus wastan sanjatane, kwanta busanane murub, Ida ang Hyang Rudra murti, Kaja kauhe pinuji, Dewatane hyang Sangkara, Sanjatane umbul umbul, Gadang warnaneki.

Artinya:

a. Dari arah timur beliau tiba, bersenjata Bajra utama, serba putih busanaNya, Sang Hyang Iswara yang utama, Dari selatan muncul, bersenjatakan Gada yang sangat kuat, busananya merah berkilau, Hyang Brahma tersohor.

b. Di bagian barat beliau turun, Senjatanya Nagapasa, BusanaNya kuning mulus, Sang Hyang Maha Desa tiada lain. Dari utara beliau muncul, senjatanya Cakra utama, Beliau Sang Hyang Wisnu, BusanaNya serba hitam.

c. Di tengan turun bhatara, Padma Merta senjatanya, Busananya warna lima, Bhatara Siwa dipuja, di atas Padmasana stananya pancaran sinarnya sangat utama, „ujwala seumunu" beristana langit.

d. Dari tenggara tiba, Tri Sula senjatanya, yang disebut Sang Hyang Sambhu, busananya berwarna abu abu sari. 
Tiba dari barat daya, senjatanya bernama Angkus, busananya berwarna kwanta, Beliau Sang Hyang Rudra murti, arah Barat Daya sangat mulia, Dewanya Hyang Sangkara, Senjatanya umbul umbul hijau.

\section{Narasi Theologis Tuhan sebagai Pencipta dan Penguasa "Tri Loka"}

Akibat "Tapa" yang dilakukan oleh Hyang Widhi terjadilah asal yaitu kekuatan Kejiwaan dan kekuatan kebendaan yang bertemu maka terciptalah alam semesta ini secara bertahap (Upadeca, 14:2006). Alam semesta (Bhuwana Agung) beserta seluruh lapisan lapisan dimensinya. Ada alam materi (tempat mahluk hidup) dan alam-alam halus. Secara garis besar bisa dikelompokkan menjadi tiga, yang disebut Triloka yaitu Bhur Loka (lapisan lapisan dimensi alam negatif, Bvah Loka (lapisan dimensi siklus samsara, siklus kehidupan kematian) dan Svah Loka (lapisan-lapisan dimensi alam positif) (http://www.facebook.com/note.php/noteid=391641441721). Hyang Widhi diyakini sebagai Pencipta dan Penguasa ketiga dunia (Tri Loka) tersebut seperti dinyatakan dalam Kidung Panca Yadnya Berikut:

Ong sembah ninganatha tinghalana de tri loka sarana,

Wahya dhyatmika sembahing hulun ijongta tan hana waneh,

Sang luir agni sakeng tahen kadi minyak sakeng dadi kita,

Sang Saksat metu yan hana wwang ngamuter tutur pinahayu

(Kakawin Aruna Wiwaha, dala Surada, 2005: 16-17)

Artinya:

Ya Tuhan sembah hamba ini orang hina,

berkenan disaksikan oleh Mu penguasa ketiga dunia,

Lahir bhatin sembah hamba kehadapan kakiMu tiada lain,

Engkau bagaikan api yang keluar dari kayu bakar kering,

bagaikan minyak yang keluar dari santan, bathin dengan baik.

Engkau seakan akan nyata tampak (keluar) apabila ada orang yang mengolah ilmu

Triloka yaitu : Bhur Loka, Bwah Loka dan Svah Loka. Yaitu pembagian dari alam semesta (Bhuwana agung) berdasarkan atas liga kelompok. Yaitu alam Swah Loka (alam sorga), para Dewa dan Hyang Widhi, Bhwah loka alam kita ini, Bhur loka adalah alam neraka. Dalam bait mantra Puja Tri Sandhya, ketiga lapisan alam ini disebutkan dikuasai oleh Tuhan (Siwa).

Berikutnya juga disebutkan bahwa Ida Hyang Widhi (Tuhan Yang Maha Esa) bersifat meresapi dan meliputi seluruh alam semesta beserta isinya. Lahir, hidup, dan musnahnya segala yang ada Beliaulah penyebabnya. Beliaulah asal dan tujuan alam semesta beserta isinya seperti dinyatakan pada bait Kidung Panca Yadnya (Wirama Mridukomala) seperti berikut:

Wyāpiwyā sārining paramatattwa durlabha kita,

Icchān tāng hanā ganalalit lawan hala hayu,

Uttpatti sthti linaning dadi kita ta kāraña,

Sang Sangkan paraning sarāt sakala siskalātmaka kita

Artinya:

(Kakawin Arjuna Wiwaha, dalam Surada, 17-18: 2005)

Engkau meresap dan meliputi,

intisari hakekat tertinggi yang sulit dicapai,

Seturut kehendakMulah ada dan tiada besar dan halus serta buruk dan baik,

Lahir dan lenyapnya segala yang ada Engkaulah pula penyebabnya,

Engkaulah Sang Asal dan tujuan alam semesta dan intisari (jiwa) alam sakala dan niskala 


\section{Narasi Theologis Pembatinan Tuhan dalam Kidung Panca Yadnya}

Secara spiritual sebagai pemeluk agama yang menyembah Tuhan adalah ingin merasakan eksistensi Beliau baik secara lahir dan bhatin. Kemampuan untuk berempati (menghayati dan merasakan) pada setiap individu tentu tidaklah sama, ada yang mampu merasakan getaran kesucian, kemahakuasaan dan keagungan Tuhan ada pula yang tidak, namun mereka yakin akan eksistensi Beliau (Tuhan/Hyang Widhi). Hal ini juga diuraikan dalam kidung Panca Yadnya (Wirama Tothāka) sebagai berikut:

Śasi wimba haneng ghața mesi bañu, Ndanasing Śuci nirmala mesi wulan, Iwa mangkana rakwa kiteng kadadin, Ringangāmbeki yoga kiteng sakala.

(Kakawin Arjuna Wiwaha dalam Surada, 2005:19-20)

Artinya:

Bagaikan bayangan bulan di dalam belanga (periuk) yang berisi air, Hanya pada setiap tempat yang suci tanpa noda berisi bayangan bulan, Seakan akan demikian engkau pada setiap mahluk, kepada orang yang melaksanakan yogalah Engkau menampakkan diri

Dalam bait kakawin diatas disebutkan bahwa "orang yang senantiasa memiliki hati yang suci dan senantiasa melaksanakan yoga samadhi akan dapat melihat bayangan wujud Tuhan. Melihat bayanga Tuhan dan senantiasa merasa dekat dengan Tuhan adalah tujuan dari penyembah yang taat. Oleh karenanya bagi penekun Yoga Marga maka sebagian besar waktunya dipergunakan untuk menghubungkan diri secara bhatin dengan Tuhan untuk dapat merasakan keberadaannya dan menerima fibrasinya.

\section{KESIMPULAN}

Dari uraian di atas maka dapat disimpulkan sebagai berikut:

1. Kidung Panca Yajnya bersifat Theologis, karena menguraikan dan menjelaskan dengan tembang (gita) yaitu pupuh, kidung dan kakawin (sekar alit, sekar madia dan sekar agung).

2. Narasi theologis tentang Tuhan dalam manifestasinya sebagai Sang Hyang Tiga Sakti yaitu Shiwa, Sada Shiwa dan Parama Shiwa, yaitu Tuhan penguasa alam semesta secara vertikal yaitu penguasa dan pelindung alam bawah (bur loka), alam tengah (bwah loka) dan alam atas (swah loka) ketiganya disebut Tri loka.

3. Narasi Theologis tentang Tuhan dalam manifestasinya sebagai pencipta Tri Bhuwana seluruh alam semesta tidak ada yang terlepas dari ciptaan Beliau jadi manusia wajib memuja dan meyembah Tuhan.

4. Narasi theologis tentang pembatinan Tuhan. Tuhan bersifat rahasia (gaib), oleh karenanya dapat dipahami oleh mereka yang taat melaksakan yoga samadhi dan olah bathin. Bagi mereka yang tekun melaksanakan yoga samadhi maka Tuhan akan tampak dalam "hatinya". Kidung Panca Yadnya juga dapat menjadikan yajnya atau upacara yang dilakukan lebih bernilai satwika (mulia).

Saran

Dari kesimpulan di atas dapat penulis sarankan sebagai berikut:

1. Mengingat Kidung Panca Yajnya memuat berbagai uraian yang bersifat theologis, yang menjelaskan tentang hakekat dan manifestasi Tuhan yang menjadi obyek pemujaan umat Hindu, maka semestinya dilakukan penelitian-penelitian yang lebih mendalam agar semakin dipahami oleh umat Hindu. 
Jurnal Widya Sastra Pendidikan Agama Hindu, Vol. 3, No. 22020

e-ISSN : 2656-7466, p-ISSN : 1907-9559

2. Kidung Panca Yajnya hendaknya semakin digali, dilestarikan dan dimasyarakatkan agar semakin berkembang dan memasyarakat.

3. Lembaga-lembaga Pesantian sebagai tempat belajar kidung hendaknya ditumbuh kembangkan.

\section{DAFTAR PUSTAKA}

Anaandakusuma, Shri Reshi, Aum Upacara Dewa Yajnya, C.V. Kayumas, 1986

Pudja, G. Bhagawad Gita (Pancama Weda). Maya Sari Jakarta, 1984.

Sabha Acarya Kota Denpasar, Dharmagita Tri Sandya, Kramaning Sembah, Program Peningkatan Pendidikan Agama dan Pendidikan Keagamaan, 2009

Surada, I Made. Dharma Gita. Kidung Pañca Yajña, Beberapa Wirama, Śloka, Phalawakya dan Macapat, Kantor Wilayah Departemen Agama Provinsi Bali, 2005

Sugeng Puji Laksono, (2006)Petualangan Antropologi. Sebuah Pengantar Ilmu Antropolgi, Penerbit : UPT. Penerbit Universitas Muhammadiyah, Malang.

Tim Penyusun, Panca Yajnya, Dewa Yajnya, Bhuta Yajnya, Resi Yajnya, Pitra

Yajnya dan Manusa Yajnya. Kantor Wilayah Departemen Agama Provinsi Bali. 2005.

Titib, I Made. Theologi \&Simbol Simbol Agama Hindu, Badan Litbang Parisadha Hindu Dharma Indonesia Pusat Bekerjasama Dengan Paramita Surabaya, 2003

Brahma Sutra Pengetahuan Tentang Tuhan, Paramita Surabaya, 2002. 